\title{
Sarcopenia: imaging assessment and clinical application
}

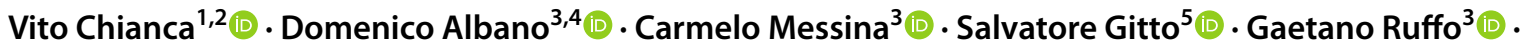 \\ Salvatore Guarino ${ }^{6}$ (1) Filippo Del Grande ${ }^{1}$ (1) - Luca Maria Sconfienza ${ }^{3,5}$ (1)
}

Received: 11 May 2021 / Revised: 21 September 2021 / Accepted: 22 September 2021 / Published online: 23 October 2021 (c) The Author(s) 2021

\begin{abstract}
Sarcopenia is a progressive, generalized skeletal muscle disorder characterized by reduction of muscle mass and strength. It is associated with increased adverse outcomes including falls, fractures, physical disability, and mortality, particularly, in elderly patients. Nowadays, sarcopenia has become a specific imaging biomarker able to predict clinical outcomes of patients. Muscle fibre reduction has shown to be an unfavourable pre-operative predictive factor in patients with cancer, and is associated with worse clinical outcomes in terms of postoperative complications, morbidity, mortality, and lower tolerance of chemoradiation therapy. Several imaging modalities, including dual-energy X-ray absorptiometry, CT, MRI, and US can be used to estimate muscle mass and quality to reach the diagnosis of sarcopenia. This article reviews the clinical implications of sarcopenia, how this condition can be assessed through different imaging modalities, and future perspectives of imaging of sarcopenia.
\end{abstract}

Keywords Body composition $\cdot$ Imaging $\cdot$ Sarcopenia $\cdot$ Muscle

\section{Introduction}

Sarcopenia has become the focus of research programmes worldwide because of its rising prevalence due to population ageing [1]. In particular, according to a systematic review, including different populations, the prevalence is higher in subjects living long term in residential care (14-33\%) compared with elderly people living in the community (1-29\%) [1]. Furthermore, worldwide prevalence of sarcopenia is expected to increase from 50 million people in 2010 to

Luca Maria Sconfienza

io@lucasconfienza.it

Vito Chianca

vitochianca@gmail.com

1 Clinica di Radiologia EOC IIMSI, Lugano, Switzerland

2 Ospedale Evangelico Betania, Napoli, Italy

3 IRCCS Istituto Ortopedico Galeazzi, Milano, Italy

4 Sezione di Scienze Radiologiche, Dipartimento di Biomedicina, Neuroscienze e Diagnostica Avanzata, Università degli Studi di Palermo, Palermo, Italy

5 Dipartimento di Scienze Biomediche per la Salute, Università degli Studi di Milano, Milano, Italy

6 IRCCS Multimedica, Milano, Italy around 200 million in 2050 [2]. For this reason, sarcopenia is considered a relevant clinical and economic issue for public healthcare and was estimated to cost around $\$ 18.5$ billion dollars in the 2000s in the United States both for direct (hospitalization) and indirect costs (nursing home admissions and home healthcare expenditure) [3].

\section{Definition and pathophysiology}

Sarcopenia, described for the first time in the 1980s, is defined at present according to the European Working Group on Sarcopenia in Older People (EWGSOP), as a "syndrome characterized by progressive and generalized loss and changes of skeletal muscle mass and strength" that occur not only in elderly patients but also in younger subjects secondary to other pathologic conditions $[4,5]$. Although the loss of muscle mass and muscle strength are distinct but interdependent factors, the loss of strength occurs faster than loss of muscle mass and seems to be a more important risk factor for adverse outcomes [6]. A multifactorial pathophysiological mechanism is the basis of sarcopenia, including genetic factors, decreased physical activity, poor nutrition, hormonal dysregulation, decreased D vitamin levels, inflammation, and cachexia due to chronic illness or cancer [7]. Ageing 
determines the imbalance between muscle protein anabolic and catabolic processes [8]. The loss of skeletal muscle mass and cellular changes are due to a reduction in size and number of myofibres $[9,10]$ and these events are partly due to the transition of muscle fibres from type II to type I with age, together with muscle fat infiltration ("myosteatosis") [11]. Notably, type I and type 2 muscle fibres differ in many aspects (fibre size, force generation, resistance, contraction speed, etc.) with the former supporting long and resistance activities, while the latter being essential for fast and powerful motor activities. Changes in neurological signalling and control mechanisms also have a crucial role in the progressive loss of muscle function due to the increase of muscle fibre denervation resulting in downregulation of the anabolic pathway [12]. Recent studies demonstrate that some changes involve the peripheral nervous system such as motor unit loss, axonal atrophy, and demyelination caused by oxidative damage to proteins and lipids, and modified transmission of impulse through the neuromuscular junction $[12,13]$. In addition, recent studies focussed on the strict interaction occurring between muscle, bone, and fat tissues and pointed out a new pathologic entity called "osteosarcopenia" or "osteosarcopenic obesity" defining combined phenotypes [14-16]. However, a consensus regarding the definition of "sarcopenic obesity" has not yet been established, and how muscle strength should be defined to make a diagnosis in these patients remains unclear $[4,17,18]$.

\section{Clinical impact of sarcopenia}

The concept of "muscle as a secretory organ" has revolutionized the idea of muscle function. Although skeletal muscle was previously considered a structure with a mere mechanical function, it has been demonstrated that muscles have various functions, both metabolic, endocrine, and neurological [19]. As an example, the relationship between sarcopenia and osteoporosis can be explained by the hyper-expression of myostatin that is a myokine with a crucial role in osteoclast formation, bone mass, and muscle mass [20, 21]. Other important hormones that take action in this relationship include growth hormone, insulin-like growth factor-1, sex hormones, and vitamin $\mathrm{D}$, which decrease with increasing age thus contributing to the development of "osteosarcopenia" [22]. Of note, sarcopenia seems to increase the risk of falls, thus increasing the risk of fractures in patients already at higher risk due to their osteoporotic condition [16].

In the respiratory system, sarcopenia leads to an increase in morbidity and mortality in chronic diseases such as cancer and chronic obstructive pulmonary disease [23]. Recently, sarcopenia has been also reported as an independent factor associated with intensive care unit admission and mortality in patients hospitalized for COVID-19 pneumonia (Fig. 1)
[24]. In inflammatory bowel disease, sarcopenia has a prevalence ranging from 27 to $61 \%$ [25], and is proven to be a negative prognostic factor for intestinal resection, especially in patients with Crohn's disease [26]. In the setting of rheumatic disorders the development of sarcopenia may reach $20 \%$ due to the underlying proinflammatory state, pain, and subsequent reduced muscle use [27].

In the endocrine system, sarcopenia is a potential cause and consequence of the diabetes mellitus [22]; the possible explanation is that patients present significantly lower skeletal muscle mass resulting in reduced capacity for glucose disposal [28]. In patients with chronic pancreatitis, malnutrition is a common sequela that alters body composition resulting in sarcopenia [29].

In several gastrointestinal and pelvic malignancies, including oesophagus, stomach, liver, pancreas, bladder, and more, sarcopenia is known to adversely affect outcomes $[30,31]$. Further, patients with reduced muscle mass have altered pharmacokinetics which cause a relative overdose in chemotherapy with consequently higher prevalence of side effects and therapy interruptions [32]. In addition, sarcopenia shows direct correlation with higher risk of post-surgical complications [33-36].

\section{Non-imaging diagnostic techniques}

Physical performance can be evaluated with a series of physical exercises taking 10-15 min to evaluate the function of lower limbs using a combination of gait speed test, repeated chair rise time, and balance tests [37]. If physical test values are below the reference values proposed by the society definitions, sarcopenia should be suspected. Anthropometry is a cheap and non-invasive technique for assessing the size, proportions, and composition of the human body; it is the most common approach for recording body composition and includes body mass index, skinfold thickness, and body circumference (waist, thigh, and calf) [38]. Bioelectrical impedance analysis is a painless and non-invasive technique that involves the application of a low-intensity electrical current through the body. The parameters obtained include resistance, which measures the impedance after the passage of current through intracellular and extracellular fluids, and the reactance, which reflects the impedance of cell membranes [39]. Virtually, all electrical impulses in the region of interest travel through the muscle, with changes in resistance and reactance reflecting variations in the muscle tissue itself [40]. It should be taken into account that measurement errors may be due to changes in hydration, soft-tissue oedema, exercise status, or food intake [41]. However, the equipment for bioelectrical impedance analysis is not widely available and is not presently suitable for clinical application. Further, biochemical and laboratory markers such as 
Fig. 1 Computed tomography images of two patients affected by COVID-19 pneumonia. Images $\mathbf{A}$ and $\mathbf{B}$ refer to a sarcopenic male patient (skeletal muscle index of $42 \mathrm{~cm}^{2}$ / $\mathrm{m}^{2}$ ) with severe parenchymal disease extent, while images $\mathbf{C}$ and $\mathbf{D}$ refer to a non-sarcopenic female patient (skeletal muscle index of $55 \mathrm{~cm}^{2} / \mathrm{m}^{2}$ ) with minimal parenchymal involvement

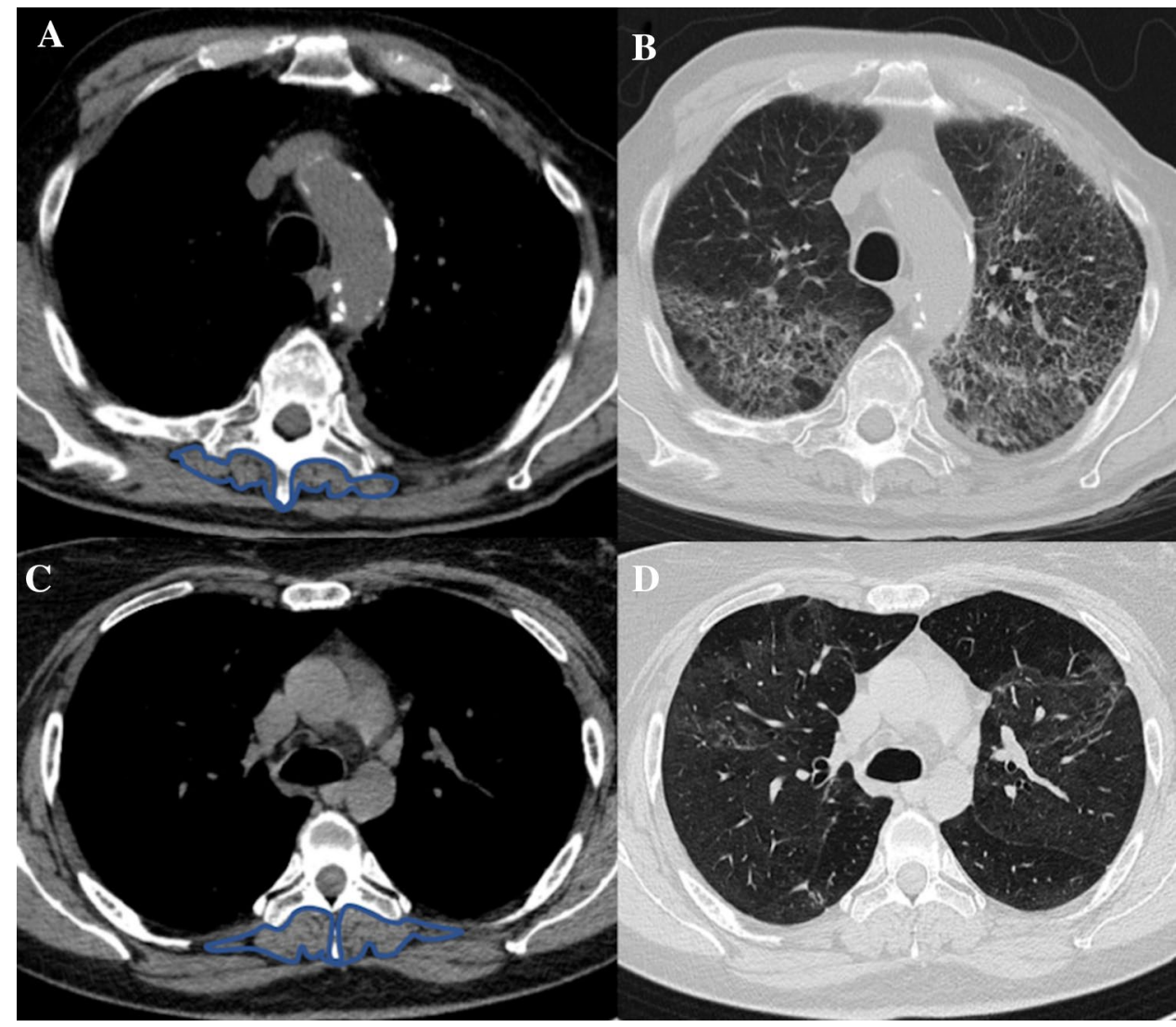

the urine measurement of deuterated creatine (D3-creatine) have shown concordance with MRI but the clinical use is still limited [22].

\section{Imaging diagnostic techniques}

\section{Dual X-ray absorptiometry (DXA)}

DXA is the most commonly used imaging technique for body composition estimation especially in non-hospitalized patients [42]. It consists of a whole-body scan performed with an emitting X-ray source at two different energy levels (40 and $70 \mathrm{keV}$ ) (Fig. 2). The radiation dose varies depending on models and manufacturers, but it is usually around $5 \mu \mathrm{Sv}$ for whole-body acquisition, which makes DXA a safe option for body composition follow-up [40]. DXA allows the measurement of lean mass (LM), fat mass (FM), and bone mineral content (BMC) simultaneously [43]. LM measurement is an estimation of all non-fat/non-bone tissues. Notably, a strong correlation has been reported in literature with LM and FM values measured on CT and MRI [44]. The sum of upper and lower limbs' LM, defined as appendicular lean mass (ALM), is used to quantify muscle mass with DXA. This value is indexed to height, and appendicular lean mass index
$\left(\mathrm{ALMI}=\mathrm{ALM} /\right.$ height $\left.^{2}\right)$ is obtained. The recent EWGSOP guidelines suggest an ALMI $<6 \mathrm{~kg} / \mathrm{m}^{2}$ in women and ALMI $<7.0 \mathrm{~kg} / \mathrm{m}^{2}$ in men as diagnostic cut-off values to define low muscle mass [5].

One of the main advantages of DXA is the capability to provide concurrently information about body composition and bone status that can be essential when evaluating disorders like osteoporosis, obesity, and cachexia [45]. Nevertheless, DXA has some limitations that should be pointed out. It is not able to quantify intramuscular adipose (in cases of myosteatosis) which impedes muscle quality estimation. Furthermore, body thickness, hydration status, and pathologic status with water retention such as heart, kidney, or liver failure can affect DXA results [46]. Indeed, DXA may overestimate muscle mass in patients with extracellular fluid accumulation, due to its inability to differentiate between water and LM tissue [47]. Conversely, DXA may underestimate trunk and thigh fat mass, and may overestimate thigh muscle mass in obese patients [48]. Finally, radiologists and radiographers should be instructed regarding the correct exam procedure, including patient positioning, demographic data collection, and image analysis in order to avoid pitfalls and misinterpretation [49]. 


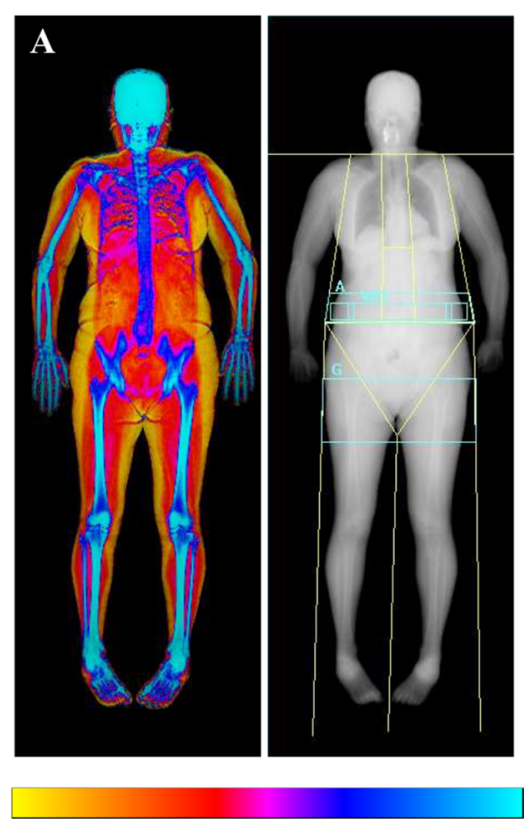

Adipose Indices

\begin{tabular}{|lrrr|}
\hline Measure & Result & \multicolumn{2}{c|}{ Percentile } \\
& & $\mathbf{Y N}$ & AM \\
Total Body \% Fat & $\mathbf{4 0 . 6}$ & $\mathbf{7 3}$ & $\mathbf{3 6}$ \\
Fat Mass/Height ${ }^{\mathbf{2}}\left(\mathrm{kg} / \mathrm{m}^{2}\right)$ & 11.2 & 69 & 41 \\
Android/Gynoid Ratio & 1.21 & & \\
\% Fat Trunk/\% Fat Legs & 1.00 & 90 & 72 \\
Trunk/Limb Fat Mass Ratio & 1.09 & 90 & 63 \\
Est. VAT Mass $(\mathrm{g})$ & 814 & & \\
Est. VAT Volume $\left(\mathrm{cm}^{3}\right)$ & 880 & & \\
Est. VAT Area $\left(\mathrm{cm}^{2}\right)$ & 169 & & \\
\hline
\end{tabular}

\section{Lean Indices}

\begin{tabular}{|lrrr|}
\hline Measure & Result & \multicolumn{2}{c|}{ Percentile } \\
& & YN & AM \\
Lean/Height ${ }^{2}\left(\mathrm{~kg} / \mathrm{m}^{2}\right)$ & 15.5 & 58 & 53 \\
Appen. Lean $/ \mathrm{Height}^{2}\left(\mathrm{~kg} / \mathrm{m}^{2}\right)$ & 6.37 & 47 & 51 \\
\hline
\end{tabular}

Est. VAT = Estimated Visceral Adipose Tissue

YN = Young Normal $\mathrm{AM}=$ Age Matched
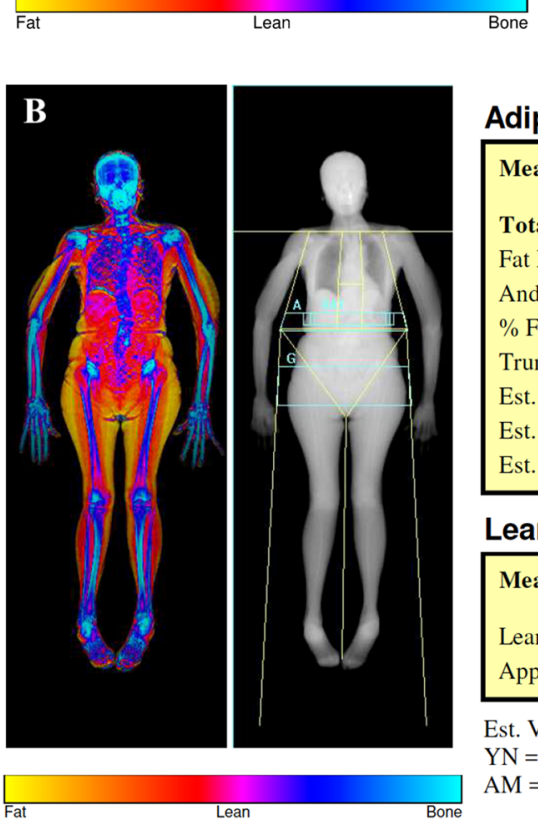

Adipose Indices

\begin{tabular}{|lrrr|}
\hline Measure & Result & YN & Percentile \\
Total Body \% Fat & $\mathbf{3 2 . 2}$ & $\mathbf{2 9}$ & $\mathbf{6}$ \\
Fat Mass/Height ${ }^{2}\left(\mathrm{~kg} / \mathrm{m}^{2}\right)$ & 5.51 & 12 & 3 \\
Android/Gynoid Ratio & 0.72 & & \\
\% Fat Trunk/\% Fat Legs & 0.62 & 15 & 3 \\
Trunk/Limb Fat Mass Ratio & 0.59 & 13 & 3 \\
Est. VAT Mass $(\mathrm{g})$ & 203 & & \\
Est. VAT Volume $\left(\mathrm{cm}^{3}\right)$ & 219 & & \\
Est. VAT Area $\left(\mathrm{cm}^{2}\right)$ & 42.0 & & \\
\hline
\end{tabular}

\section{Lean Indices}

\begin{tabular}{|lrrr|}
\hline Measure & Result & \multicolumn{2}{c|}{ Percentile } \\
& & YN & AM \\
Lean/Height ${ }^{2}\left(\mathrm{~kg} / \mathrm{m}^{2}\right)$ & 11.3 & 1 & 1 \\
Appen. Lean $/$ Height $^{2}\left(\mathrm{~kg} / \mathrm{m}^{2}\right)$ & 4.58 & 1 & 3 \\
\hline
\end{tabular}

Est. VAT = Estimated Visceral Adipose Tissue

YN = Young Normal $\mathrm{AM}=$ Age Matched

Fig. 2 Dual-energy X-ray absorptiometry body composition scan of two female patients. Image A shows a 40-year-old woman without sarcopenia, with a value of Append. Lean/Height ${ }^{2}$ (ALMI index, see the red circle) of $6.37 \mathrm{~kg} / \mathrm{m}^{2}$ (normal values $>6.0 \mathrm{~kg} / \mathrm{m} 2$ for

\section{CT}

$\mathrm{CT}$ is more and more used in research trials as routine diagnostic tool for the assessment of muscle quantity and quality, given that muscle density reduction is related to the degree of fat infiltration [7]. This imaging technique has the advantage of being performed for staging and follow-up of tumours and various other disorders, thus the assessment of sarcopenia is possible both in prospective and retrospective women according to EWGSOP2 [5]). Conversely, image B shows a 84-year-old woman with a DXA-based diagnosis of sarcopenia and a very low value of Append. Lean/Height ${ }^{2}$ (see red circle, ALMI index $=4.58 \mathrm{~kg} / \mathrm{m}^{2}$ )

analysis without the need for additional scans. To assess muscle mass and quality, it is possible to draw a region of interest (ROI) traced to evaluate the cross-sectional area (CSA) and attenutation values of the skeletal muscles [50, 51]. A valid and accurate approach to estimate muscle and whole-body composition is to draw a ROI on a single axial CT slice to obtain the CSA applying standardized thresholds ( -29 Hounsfield $\mathrm{HU} /+150 \mathrm{HU}$ ) in order to include only muscle tissue during post-processing segmentation [52]; on 
the other hand, the thresholds of adipose tissue $(-190 /-30$ HU) are applied to assess the amount of intermuscular fat tissue. In most studies, the segmentation is performed at L3 or L4 level and ROIs include psoas muscles or all present muscles (paraspinous, psoas, abdominal) on the same slice (Fig. 3) [53]. On the same CT slice it is also possible to calculate information regarding the visceral adipose tissue and subcutaneous tissues obtaining a CT body composition (Fig. 4). It is important to highlight that non-contrast images should be used because muscle attenuation values increase after intravenous contrast media injection [54]. CSA is generally indexed for height (CSA/height $\left.{ }^{2}\right)$ to obtain the skeletal muscle index. A recent meta-analysis conducted by Amini et al. showed that the most common skeletal muscle index cut-off values reported in the literature for muscle mass assessment on CT at L3 range from 52 to $55 \mathrm{~cm}^{2} / \mathrm{m}^{2}$ for men and from 39 to $41 \mathrm{~cm}^{2} / \mathrm{m}^{2}$ for women [53]. However, L3 measurements are significantly different from those of other vertebral levels [55] and these cut-offs are only applicable on abdominal CT scans, excluding imaging of the chest (for
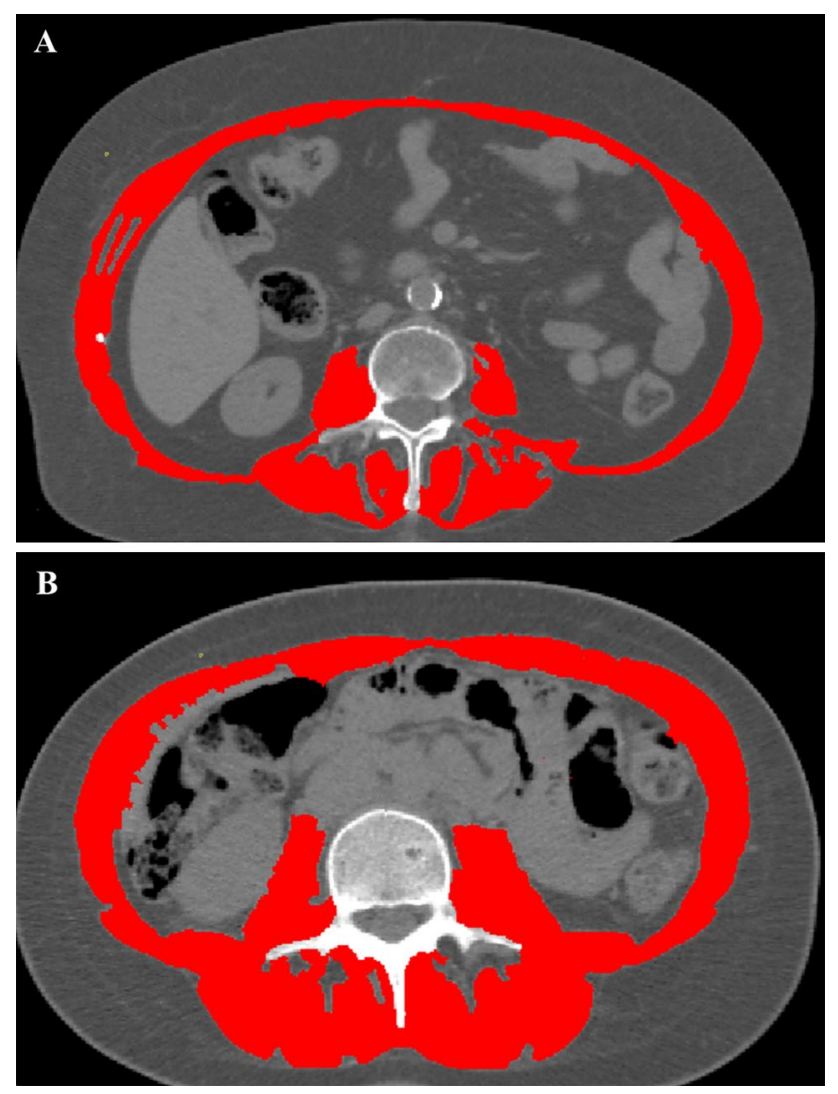

Fig. 3 Computed tomography images of typical sarcopenic (image A) and non-sarcopenic (image B) patient. Skeletal muscle area (which is shown in red) is reduced in patient A, and this is especially visible in the paraspinal muscles which are larger and less infiltrated by intramuscular fat. A skeletal muscle index of $38 \mathrm{~cm}^{2} / \mathrm{m}^{2}$ and of $58 \mathrm{~cm}^{2} / \mathrm{m}^{2}$ were calculated using the CSA and height $\left(\mathrm{CSA} /\right.$ height $\left.^{2}\right)$ of patients $\mathrm{A}$ and $\mathrm{B}$, respectively
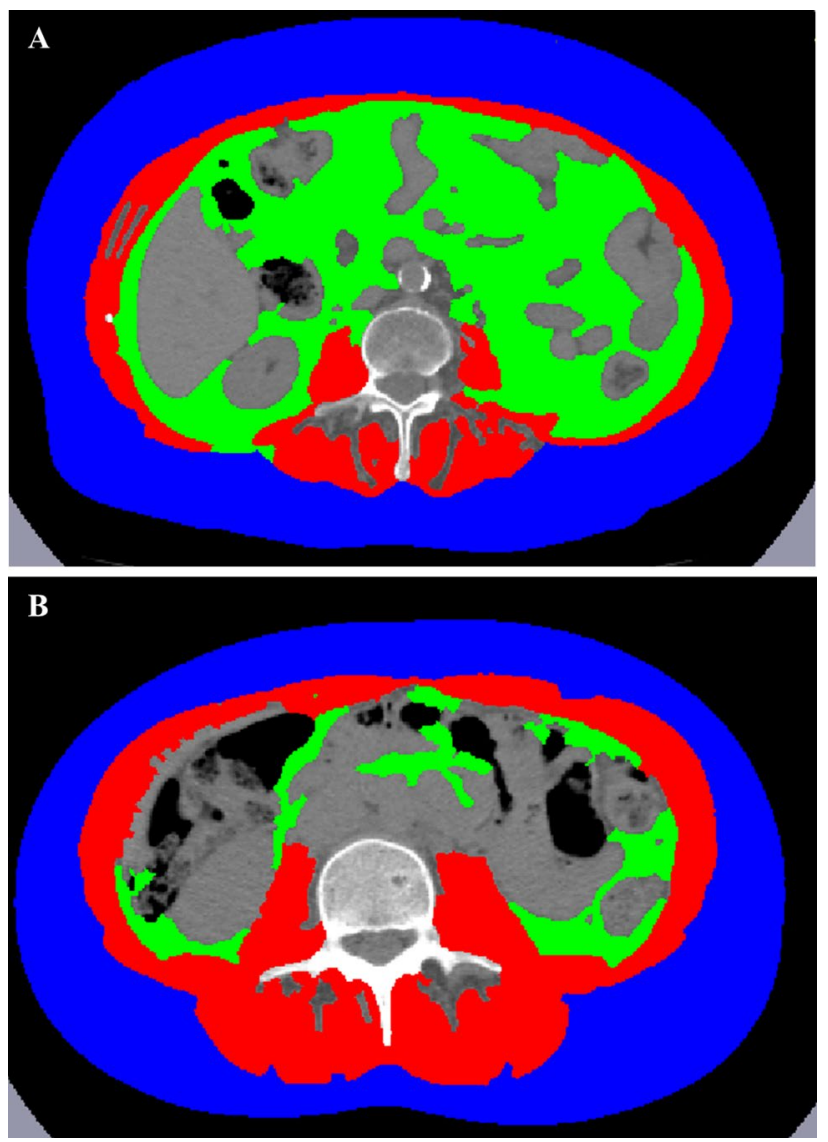

Fig. 4 Body composition on computed tomography images of the same sarcopenic (image A) and non-sarcopenic (image $\mathbf{B}$ ) patients of Fig. 2. Skeletal muscle area is shown in red colour, visceral adipose tissue area in green and subcutaneous adipose tissue in blue

example, for lung cancer screening) and of the pelvis without abdomen (in case of gynaecological cancer or hip fracture). In this regard, the skeletal muscle cut-offs from T10 to L5 reported by Derstine et al. extend sarcopenia evaluations to chest and pelvis examination to enable wider clinical applications of this imaging technique [56]. For this reason, other authors have tested the possibility to estimate muscle status around the hip to be used to predict outcomes after pelvis surgery [57]. Skeletal muscle and body composition evaluation using CT is shown in Figs. 3 and 4, respectively.

\section{MRI}

MRI enables to assess muscle composition by using several semi-quantitative or quantitative sequences without the need of ionizing radiations. Indeed, although MRI can be used to measure CSA of skeletal muscles, advanced MRI sequences allow to combine the estimation of body composition and the evaluation of muscle quality abnormalities, such as muscle disruption, oedema, fat infiltration (myosteatosis) or fibrosis (myofibrosis) [58], with the last two components 
increasing within muscles during ageing [59]. Different sequences can be used to assess sarcopenia:

- T2 mapping has been proposed as an imaging marker for fatty changes of skeletal muscle tissue [60] because it allows objective, comparable, and precise assessment of small changes in the muscle fibre composition [61]. Multi-echo sequences are used to generate T2 maps, by acquiring multiple echoes of the same image with pixel by pixel fitting of the T2 relaxation curve [62]. Measurements of $\mathrm{T} 2$ relaxation times can be used to identify pathological increase of $\mathrm{T} 2$ values of fat-infiltrated muscles in sarcopenic patients due to microstructural changes [63]. Currently, the T2 mapping in sarcopenia has been used only for research purposes and no cut-off values are available to differentiate sarcopenic from non-sarcopenic patients, thus its use in clinical practice still needs to be validated.

- MR spectroscopy is a functional non-invasive imaging technique that provides information regarding the biochemical processes within the body. There are theoretical advantages to multivoxel spectroscopy for sarcopenia evaluation because it can provide quantitative information related to a ROI due to the processing of several smaller voxels simultaneously, in comparison to single voxel spectroscopy, which represents the entire muscle belly, but additional evaluation is required [64]. However, multivoxel spectroscopy has rarely been used in sarcopenia and more clinical research will be required to clarify the actual role of this technique in sarcopenia [65].

- Dixon sequences overcome the limited applicability of MR spectroscopy due to inhomogeneity of fat muscle infiltration, thereby allowing precise quantitative assessment of sarcopenia [66] (Fig. 5). From a technical point of view, two- or multi-point Dixon sequences offer the possibility to obtain two separate "fat only" and "water only" images, through the acquisition of two or more echoes at different echo times [67]. The first acquisition is performed at an echo time when fat and water protons are in phase, while a second acquisition is then performed at an echo time in which the protons are out of phase [68]. Moreover, another advantage is the possibility to combine dixon with different types of sequences, both gradient and spin echo, and with different weightings (T1-w, T2-w or PD-w) [69]. Studies demonstrated that Dixon shows high accuracy in the detection and quantification of fatty replacement within muscles in dystrophic [70] or diabetes mellitus patients [71]. Despite these advantages, this sequence requires long acquisition time and is sensitive to metal artifacts in case of prostheses [68].
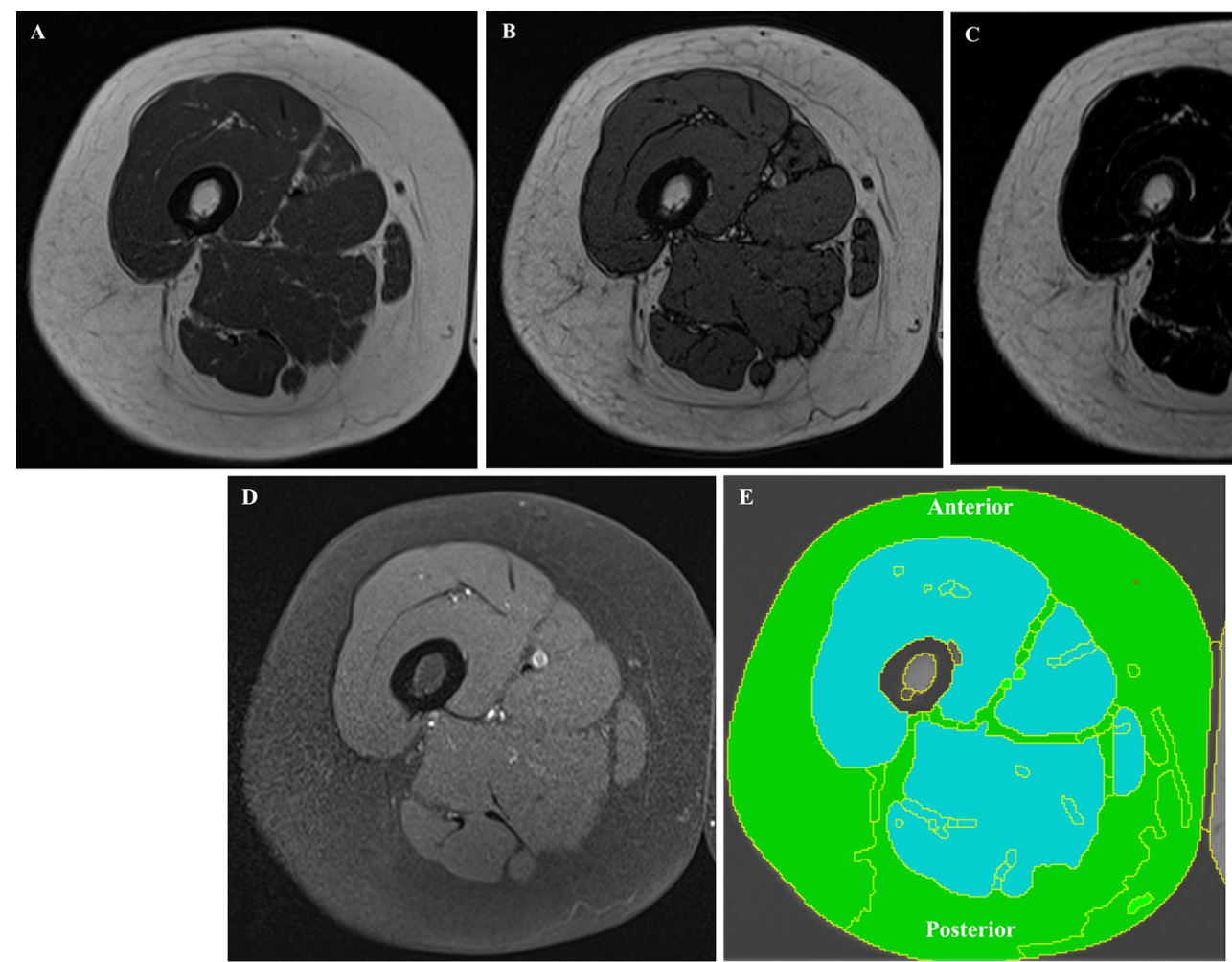

Fig. 5 Dixon magnetic resonance sequence acquired on the right thigh of a 62-year-old woman. Axial T1W in-phase (image A), outof-phase (image B), $100 \%$ fat images (image C), and 100\% water

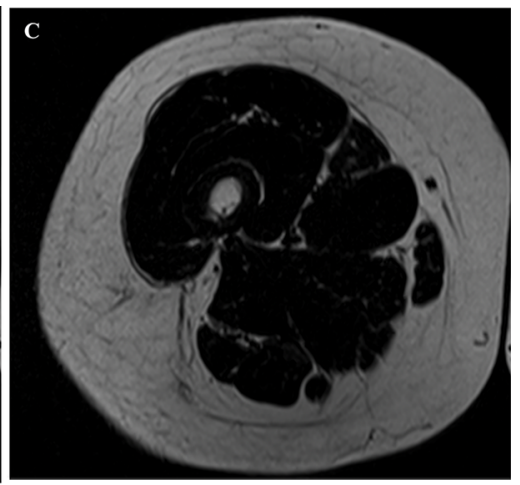

images (image D). After post-processing, a semi-automatic segmentation can be obtained (image E) showing fat (green) and muscle tissue (turquoise) separately in the same slice 
- Diffusion tensor imaging is an advanced MRI sequence, traditionally used for tracking track fibre course in the central nervous system that offers the possibility of detecting and quantifying muscle fibre fat replacement $[72,73]$. Fractional anisotropy is a parameter, ranging between 0 and 1 , used to quantify the directional orientation of water molecules as an indirect sign of microstructural fibre changes [74]. It seems that fat replacement presents a positive correlation with fractional anisotropy values in sarcopenic patients and negative correlation with apparent diffusion coefficient [75]. Further, diffusion tensor imaging tractography demonstrates the decrease in fibre length, number, and architecture, providing further quantitative information. This sequence is still under investigation in several studies as a promising non-invasive imaging tool to assess quantitatively muscle status and fat replacement, but its clinical value needs to be proven.

Although MRI is a promising technique in sarcopenia, with the advantages of no radiation exposure and excellent accuracy in measuring quantitative and qualitative parameters of skeletal muscle, it is still confined to the research stage with scarce application in clinical practice due to the high cost, lengthy acquisition, and lack of cut-off values and standardized protocols.

\section{US}

US is a portable, inexpensive, non-invasive technique without ionizing radiations widely used to investigate musculoskeletal conditions [76]. It has already proven its worth in the assessment of muscle quality and quantity [77] as an accurate technique for the estimation of muscle properties showing strong positive correlation with DEXA [78], CT [79] and MRI-based measurements [80]. Previous studies showed good intra- and inter-rater reliability both in elderly people [81] and younger population [82]. US also provides information about muscle echotexture depending on the degree of intramuscular fat and connective tissue infiltration [83]. There are five components that can be easily measured when assessing muscle components in sarcopenic patients: muscle thickness, pennation angle, fascicle length, echo intensity, and CSA [84]. However, it is unclear which anatomical site is best for specific outcomes as a prediction of total skeletal muscle mass. The majority of studies have been performed on the quadriceps muscle, while few have focussed on others, such as postural muscles $[83,85,86]$. When measuring the maximal thickness and CSA of a muscle, it is advised to take the midpoint of the muscle between the tendons, and the point halfway between the medial and lateral border of the muscle belly [87] (Fig. 6). The pennation angle and
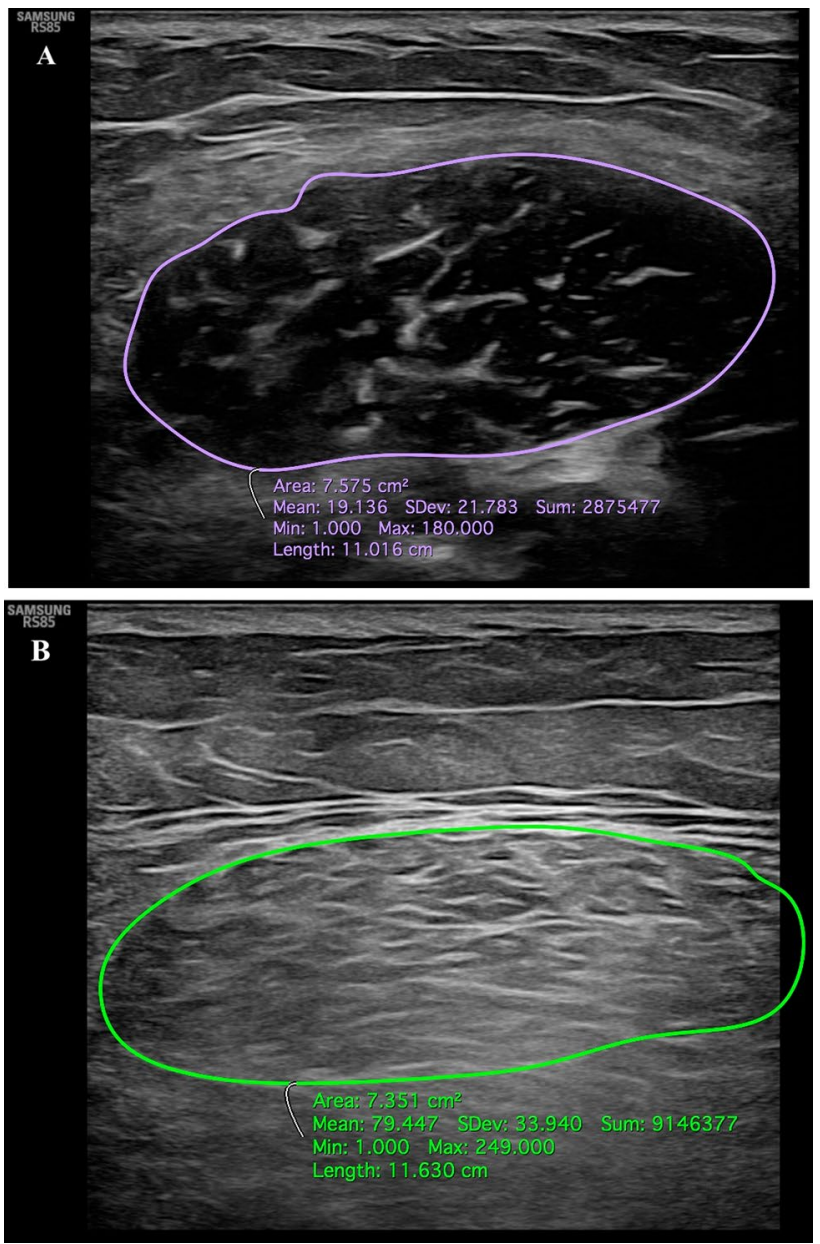

Fig. 6 Ultrasound transverse images of the proximal third of the rectus femoris of two female patients with similar age and BMI. Image A shows the rectus femoris of 38-year-old runner $(B M I=24.2)$, while image $\mathbf{B}$ shows the rectus anterior of a 42-year-old patient $(\mathrm{BMI}=25.1)$ who does not practice any physical activity. Despite a similar muscle trophism (CSA of patient in image $\mathbf{B}=7.575 \mathrm{~cm}^{2}$, CSA of patient in image $\mathrm{B}=7.351 \mathrm{~cm}^{2}$ ), an increased muscle belly echogenicity can be observed in the patient with limited physical activity due to fatty infiltration (image $\mathbf{B}$ )

muscle fascicle length must be assessed at rest and during contraction. These parameters are significantly associated with the loss of maximum force and shortening velocity of muscle fibres in sarcopenic patients [88]. The geometrical arrangement of muscles should be considered as it impacts on the generation of muscle force. The pennation angle can be calculated between the longitudinal axis of the muscle belly and its fibres. It is an important point given that the muscle force is related to its shortening velocity, so the slower shortening velocity of pennate muscle fascicles can lead to greater muscle force. Hence, the obliqueness of muscle fascicles and their rotation within the muscle belly enable them to be geared to slower speeds of contraction than the muscle belly, giving them higher force 
potentials. Structural changes associated with sarcopenia, including muscle size reduction and shortening of fascicles that become less pennate, have been associated with lower performance in elderly [85]. Notably, the anatomical CSA (ACSA), which is the CSA perpendicular to the longitudinal axis of the muscle belly, should be distinguished from the physiological CSA (PCSA), which is the CSA perpendicular to muscle fibres. The latter better describes the contraction properties of pennate muscles, indeed, while the ACSA and the PCSA are the same in non-pennate muscles, they differ in pennate muscles in which the ACSA underestimates the number of total fibres. In this setting, muscle strength is more closely correlated with PCSA, which is defined as the CSA of a muscle perpendicular to its fibres, because the former represents the maximum number of actomyosin crossbridges that can be activated during contraction $[84,89]$.

US elastography has been proposed as an investigative tool for muscle stiffness using shear-wave elastography and correlates with lower stiffness values in both lower and upper limb skeletal muscle in elderly [90]. Contrastenhanced US has also been proposed as a US tool for assessing changes in microvasculature associated with sarcopenia but this point has been scarcely investigated in the previous studies [91]. Even though US shows promising results for the investigation of sarcopenia, the lack of standardized cut-off values strongly limits its validation for the clinical practice [92]. We have resumed in Table 1 the strengths and weak points of imaging modalities used to assess sarcopenia.

\section{The role of artificial intelligence (AI) in sarcopenia}

$\mathrm{AI}$ is a field of computer science dedicated to the creation of systems performing tasks that usually require human intelligence, thus allowing machines to better interpret huge amounts of data [93]. This is a group of different subfields but the most important areas in radiology are machine learning and deep learning [94]. With machine learning different algorithms are trained to recognize specific characteristics by learning patterns from datasets $[95,96]$.

In sarcopenia, AI determines an automated CT segmentation of muscle, bone, and adipose tissues, allowing a broad use of prospective or retrospective analysis of CT or MRI images $[7,97]$. The data generated by software may be independent to the interobserver variability in sarcopenia quantification. Dong et al. analysed CT images of 99 patients with advanced non-small cell lung cancer, with 40 of them having been identified as sarcopenic using skeletal muscle CSA at the L3 vertebral level; the authors extracted 854 radiomic and clinical features from the skeletal muscle area at the 12th thoracic vertebra level and five optimal features were selected [98]. An automated muscle measurement on a single-slice chest CT at T12 vertebral level was used by Lenchik et al. to determine a relationship between muscle

Table 1 Advantages and disadvantages of the main imaging tools for the assessment of body composition and mass/fat assessment

\begin{tabular}{|c|c|c|c|}
\hline Technique & Strengths & Weak points & Measurements \\
\hline DXA & $\begin{array}{l}\text { - Fast acquisition } \\
\text { - Widely available } \\
\text { - Accurate and reproducible } \\
\text { - Validated cut-off values } \\
\text { - Minimal irradiation } \\
\text { - Cheap }\end{array}$ & $\begin{array}{l}\text { - Different results varying the densitometer brands } \\
\text { - Dependent by hydration status } \\
\text { - Bidimensional data }\end{array}$ & $\begin{array}{l}\text { - Appendicular lean mass (ALM) } \\
\text {-Appendicular lean mass index (ALMI) }\end{array}$ \\
\hline $\mathrm{CT}$ & $\begin{array}{l}\text { - Fast acquisition } \\
\text { - Widely available } \\
\text { - Accurate and reproducible } \\
\text { - High spatial resolution }\end{array}$ & $\begin{array}{l}\text { - Non-negligible irradiation } \\
\text { - Cut-off values are still not used in clinical practice } \\
\text { - Expensive } \\
\text { - Time-consuming segmentation process }\end{array}$ & $\begin{array}{l}\text { - CSA indexed by height }{ }^{2}(\mathrm{SMI}) \\
\text { - Attenuation values }\end{array}$ \\
\hline MRI & $\begin{array}{l}\text { - Accurate and reproducible } \\
\text { - No irradiation } \\
\text { - High contrast resolution } \\
\text { - Capability to identify } \\
\text { muscle oedema and fat } \\
\text { infiltration } \\
\text { - Promising advanced } \\
\text { sequences }\end{array}$ & $\begin{array}{l}\text { - Long acquisition time } \\
\text { - No validated cut-off values for sarcopenia } \\
\text { - Expensive } \\
\text { - Lower availability } \\
\text { - Long post-processing of advanced sequences }\end{array}$ & $\begin{array}{l}\text { - CSA indexed by height }{ }^{2} \text { (SMI) } \\
\text { - Fat content on DIXON } \\
\text { - Experimental measurements of advanced } \\
\text { sequences (ADC, FA, T2 relaxation } \\
\text { time..) }\end{array}$ \\
\hline US & $\begin{array}{l}\text { - Fast acquisition } \\
\text { - Widely available } \\
\text { - No irradiation exposure } \\
\text { - Cheap } \\
\text { - Real-time imaging }\end{array}$ & $\begin{array}{l}\text { - Scarcely reproducible } \\
\text { - Poor accuracy } \\
\text { - No validated cut-off values for sarcopenia }\end{array}$ & $\begin{array}{l}\text { - CSA indexed by height }{ }^{2}(\mathrm{SMI}) \\
\text { - Muscle thickness and echogenicity }\end{array}$ \\
\hline
\end{tabular}


measurement with the rate of survival in a large patient population of 6.803 men and 4.558 women. Paraspinous muscles were segmented and the CSAs were recorded. The automated machine learning process found a significant relationship between lower paraspinous skeletal muscle area/ density and worse patient survival [99].

Barnard et al. trained a convolutional neural network to perform muscle segmentation at $\mathrm{T} 12$ on a training dataset of 1875 single-slice CT images acquired on 4 different scanner manufacturers and tested their accuracy on 209 different CT images. The machine learning algorithm measurements of the CSA and the muscle attenuation of the left paraspinous muscle were compared with that of manual segmentation using Dice similarity coefficients and Pearson correlations. They found a favourable correlation of the machine learning algorithm compared to manual segmentation for measurement of paraspinous muscles with a Dice score of 0.94 [100]. AI could help segmenting skeletal muscles in a short time and as precisely as trained subjects. In the future, automated CT or MRI analysis will reduce the time-consuming segmentation process and will be used to classify patients at risk for sarcopenia to predict prognosis or to recommend follow-up and potential therapeutic interventions.

Recently, a different AI approach has been tested to assess body composition; Kim used radiomic features extracted from CT images to identify sarcopenia in non-small cell lung carcinoma patients reporting interesting results [101]. Indeed, the concept of radiomics, understood as the conversion of images to a huge amount of data, could be the future of imaging assessment of sarcopenia. To date, radiomics has been mostly used in oncology to predict the outcome of patients with cancers, but the potential use of radiomic features to facilitate the diagnosis of sarcopenia could be the subject of future investigations.

\section{Conclusion}

Sarcopenia is a chronic disease with increasing prevalence among older adults. This condition is associated with worse outcome of several disorders with non-negligible economic burden of the healthcare system. Several imaging modalities can be used to assess sarcopenia, with the reduction of muscle mass on CSA being the main diagnostic finding. DXA is the most widely used imaging modality with defined cut-off values to identify patients affected by sarcopenia, while CT and MRI are mainly used for research purposes, despite they are reliable cross-sectional techniques with the ability to reveal both quantitative and qualitative changes in muscle mass. US is another imaging technique able to assess the muscle status, but still with a marginal role in sarcopenia imaging. The most recent studies on AI are mostly focussed on the reduction of the time-consuming process of muscles segmentation to measure CSA and muscle composition with the purpose to make easier to screen categories at risk of sarcopenia. Muscles are almost invariably included on diagnostic scans and radiologists must be aware of the prognostic role of sarcopenia as a more and more interesting imaging biomarker.

Funding Open access funding provided by Università degli Studi di Milano within the CRUI-CARE Agreement. No funding has been received for the present paper.

\section{Declarations}

Conflict of interest FDG receives institutional reference and research center for Siemens. None of the other authors have conflict of interest to declare.

Ethical approval Not Applicable.

Consent to participate Not Applicable.

Consent for publication Not Applicable.

Open Access This article is licensed under a Creative Commons Attribution 4.0 International License, which permits use, sharing, adaptation, distribution and reproduction in any medium or format, as long as you give appropriate credit to the original author(s) and the source, provide a link to the Creative Commons licence, and indicate if changes were made. The images or other third party material in this article are included in the article's Creative Commons licence, unless indicated otherwise in a credit line to the material. If material is not included in the article's Creative Commons licence and your intended use is not permitted by statutory regulation or exceeds the permitted use, you will need to obtain permission directly from the copyright holder. To view a copy of this licence, visit http://creativecommons.org/licenses/by/4.0/.

\section{References}

1. 1. Cruz-Jentoft AJ, Landi F, Schneider SM, et al (2014) Prevalence of and interventions for sarcopenia in ageing adults: A systematic review. Report of the International Sarcopenia Initiative (EWGSOP and IWGS). Age Ageing 43:48-759 . doi: https:// doi.org/10.1093/ageing/afu115

2. 2. Cruz-Jentoft AJ, Baeyens JP, Bauer JM, et al (2010) Sarcopenia: European consensus on definition and diagnosis: Report of the European Working Group on Sarcopenia in Older People. Age Ageing 39:412-423 . doi: https://doi.org/10.1093/ageing/ afq034

3. 3. Beaudart C, Rizzoli R, Bruyère O, et al (2014) Sarcopenia: burden and challenges for public health. Arch Public Heal 72:45 . doi: https://doi.org/10.1186/2049-3258-72-45

4. 4. Cruz-Jentoft AJ, Sayer AA (2019) Sarcopenia. Lancet 393:2636-2646

5. 5. Cruz-Jentoft AJ, Bahat G, Bauer J, et al (2019) Sarcopenia: revised European consensus on definition and diagnosis. Age Ageing 48:16-31 . doi: https://doi.org/10.1093/ageing/afy169 
6. 6. Wall BT, Dirks ML, Van Loon LJC (2013) Skeletal muscle atrophy during short-term disuse: Implications for age-related sarcopenia. Ageing Res. Rev. 12:898-906

7. 7. Lenchik L, Boutin RD (2018) Sarcopenia: Beyond Muscle Atrophy and into the New Frontiers of Opportunistic Imaging, Precision Medicine, and Machine Learning. Semin Musculoskelet Radiol 22:307-322 . doi: https://doi.org/10.1055/s-00381641573

8. 8. Ali S, Garcia JM (2014) Sarcopenia, cachexia and aging: Diagnosis, mechanisms and therapeutic options - A mini-review. Gerontology 60:294-305

9. 9. Verdijk LB, Snijders T, Drost M, et al (2014) Satellite cells in human skeletal muscle; from birth to old age. Age (Omaha) 36:545-557 . doi: https://doi.org/10.1007/s11357-013-9583-2

10. 10. Vitale JA, Bonato M, Borghi S, et al (2020) Home-based resistance training for older subjects during the COVID-19 outbreak in Italy: Preliminary results of a six-months RCT. Int J Environ Res Public Health 17:9533 . doi: https://doi.org/10.3390/ ijerph 17249533

11. 11. Ciciliot S, Rossi AC, Dyar KA, et al (2013) Muscle type and fiber type specificity in muscle wasting. Int. J. Biochem. Cell Biol. 45:2191-2199

12. 12. Manini TM, Hong SL, Clark BC (2013) Aging and muscle: A neuron?s perspective. Curr. Opin. Clin. Nutr. Metab. Care $16: 21-26$

13. 13. Brioche T, Pagano AF, Py G, Chopard A (2016) Muscle wasting and aging: Experimental models, fatty infiltrations, and prevention. Mol Aspects Med 50:56-87 . doi: https://doi.org/10. 1016/j.mam.2016.04.006

14. 14. Hirschfeld HP, Kinsella R, Duque G (2017) Osteosarcopenia: where bone, muscle, and fat collide. Osteoporos. Int. 28:2781-2790

15. 15. Kalinkovich A, Livshits G (2017) Sarcopenic obesity or obese sarcopenia: A cross talk between age-associated adipose tissue and skeletal muscle inflammation as a main mechanism of the pathogenesis. Ageing Res. Rev. 35:200-221

16. 16. Vitale JA, Messina C, Albano D, et al (2021) Appendicular Muscle Mass, Thigh Intermuscular Fat Infiltration, and Risk of Fall in Postmenopausal Osteoporotic Elder Women. Gerontology 67:415-424. doi: https://doi.org/10.1159/000513597

17. 17. Barazzoni R, Bischoff SC, Boirie Y, et al (2018) Sarcopenic obesity: Time to meet the challenge. Clin Nutr 37:1787-1793 . doi: https://doi.org/10.1016/j.clnu.2018.04.018

18. 18. Scott D, Sanders KM, Aitken D, et al (2014) Sarcopenic obesity and dynapenic obesity: 5-year associations with falls risk in middle-aged and older adults. Obesity 22:1568-1574 . doi: https://doi.org/10.1002/oby.20734

19. 19. Lee K, Shin Y, Huh J, et al (2019) Recent issues on body composition imaging for sarcopenia evaluation. Korean J. Radiol. 20:205-217

20. 20. Dankbar B, Fennen M, Brunert D, et al (2015) Myostatin is a direct regulator of osteoclast differentiation and its inhibition reduces inflammatory joint destruction in mice. Nat Med 21:1085-1090 . doi: https://doi.org/10.1038/nm.3917

21. 21. Messina C, Monaco CG, Ulivieri FM, et al (2016) Dualenergy X-ray absorptiometry body composition in patients with secondary osteoporosis. Eur J Radiol 85:1493-1498 . doi: https:// doi.org/10.1016/j.ejrad.2016.03.018

22. 22. Cochenski Borba VZ, Costa TL, Moreira CA, Boguszewski CL (2019) Mechanisms of endocrine disease sarcopenia in endocrine and non-endocrine disorders. Eur. J. Endocrinol. 180:R185-R199

23. 23. Kalyani RR, Corriere M, Ferrucci L (2014) Age-related and disease-related muscle loss: The effect of diabetes, obesity, and other diseases. Lancet Diabetes Endocrinol. 2:819-829
24. 24. Schiaffino S, Albano D, Cozzi A, et al (2021) CT-derived Chest Muscle Metrics for Outcome Prediction in Patients with COVID-19. Radiology 300:E328-E336. doi: https://doi.org/10. 1148/radiol.2021204141

25. 25. Ryan E, McNicholas D, Creavin B, et al (2019) Sarcopenia and inflammatory bowel disease: A systematic review. Inflamm. Bowel Dis. 25:67-73

26. 26. Bamba S, Sasaki M, Takaoka A, et al (2017) Sarcopenia is a predictive factor for intestinal resection in admitted patients with Crohn's disease. PLoS One 12:e0180036 . doi: https://doi.org/ 10.1371/journal.pone.0180036

27. 27. Barone M, Viggiani M, Anelli M, et al (2018) Sarcopenia in Patients with Rheumatic Diseases: Prevalence and Associated Risk Factors. J Clin Med 7:504 . doi: https://doi.org/10.3390/ jcm7120504

28. 28. McKee A, Morley JE, Matsumoto AM, Vinik A (2017) Sarcopenia: An endocrine disorder? Endocr. Pract. 23:1143-1152

29. 29. Kuan LL, Dennison AR, Garcea G (2021) Prevalence and Impact of Sarcopenia in Chronic Pancreatitis: A Review of the Literature. World J. Surg. 45:590-597

30. 30. Anjanappa M, Corden M, Green A, et al (2020) Sarcopenia in cancer: Risking more than muscle loss. Tech Innov Patient Support Radiat Oncol 16:50-57 . doi: https://doi.org/10.1016/j. tipsro.2020.10.001

31. Gourd E (2018) Sarcopenia and adiposity linked to overall survival. Lancet. Oncol. 19:e239

32. 32. Prado CMM, Lima ISF, Baracos VE, et al (2011) An exploratory study of body composition as a determinant of epirubicin pharmacokinetics and toxicity. Cancer Chemother Pharmacol 67:93-101 . doi: https://doi.org/10.1007/s00280-010-1288-y

33. 33. Babu JM, Kalagara S, Durand W, et al (2019) Sarcopenia as a Risk Factor for Prosthetic Infection After Total Hip or Knee Arthroplasty. J Arthroplasty 34:116-122 . doi: https://doi.org/10. 1016/j.arth.2018.09.037

34. 34. de Jong MC, Patel N, Hassan-Smith Z, et al (2021) Sarcopenia is Associated with Reduced Survival following Surgery for Adrenocortical Carcinoma. Endocr Res 1-10 . doi: https://doi. org/10.1080/07435800.2021.1954942

35. 35. Chakedis J, Spolverato G, Beal EW, et al (2018) Pre-operative Sarcopenia Identifies Patients at Risk for Poor Survival After Resection of Biliary Tract Cancers. J Gastrointest Surg 22:1697-1708 . doi: https://doi.org/10.1007/s11605-018-3802-1

36. 36. Sakurai K, Kubo N, Tamamori Y, et al (2021) Depletion of skeletal muscle mass adversely affects long-term outcomes for men undergoing gastrectomy for gastric cancer. PLoS One 16:e256365 . doi: https://doi.org/10.1371/journal.pone.02563 65

37. 37. Mijnarends DM, Schols JMGA, Meijers JMM, et al (2015) Instruments to Assess Sarcopenia and Physical Frailty in Older People Living in a Community (Care) Setting: Similarities and Discrepancies. J Am Med Dir Assoc 16:301-308 . doi: https:// doi.org/10.1016/j.jamda.2014.11.011

38. 38. Al-Gindan YY, Hankey C, Govan L, et al (2014) Derivation and validation of simple equations to predict total muscle mass from simple anthropometric and demographic data. Am J Clin Nutr 100:1041-1051 . doi: https://doi.org/10.3945/ajen.113. 070466

39. Faes TJC, Van Der Meij HA, De Munck JC, Heethaar RM (1999) The electric resistivity of human tissues (100 HZ-10 MHZ): A meta- analysis of review studies. Physiol. Meas. 20

40. 40. Tosato M, Marzetti E, Cesari M, et al (2017) Measurement of muscle mass in sarcopenia: from imaging to biochemical markers. Aging Clin Exp Res 29:19-27 . doi: https://doi.org/10.1007/ s40520-016-0717-0

41. 41. Yoshida D, Suzuki T, Shimada H, et al (2014) Using two different algorithms to determine the prevalence of sarcopenia. 
Geriatr Gerontol Int 14:46-51 . doi: https://doi.org/10.1111/ggi. 12210

42. 42. Albano D, Messina C, Vitale J, Sconfienza LM (2019) Imaging of sarcopenia: old evidence and new insights. Eur Radiol 30:2199-2208 . doi: https://doi.org/10.1007/s00330-019-06573-2

43. 43. Messina C, Albano D, Gitto S, et al (2020) Body composition with dual energy X-ray absorptiometry: from basics to new tools. Quant Imaging Med Surg 10:1687-1698 . doi: https://doi.org/10. 21037/qims.2020.03.02

44. 44. Guglielmi G, Ponti F, Agostini M, et al (2016) The role of DXA in sarcopenia. Aging Clin. Exp. Res. 28:1047-1060

45. 45. Messina C, Maffi G, Vitale JA, et al (2018) Diagnostic imaging of osteoporosis and sarcopenia: A narrative review. Quant. Imaging Med. Surg. 8:86-99

46. 46. Prado CMM, Heymsfield SB (2014) Lean tissue imaging: A new era for nutritional assessment and intervention. J Parenter Enter Nutr 38:940-953 . doi: https://doi.org/10.1177/01486 07114550189

47. 47. Proctor DN, O'Brien PC, Atkinson EJ, Nair KS (1999) Comparison of techniques to estimate total body skeletal muscle mass in people of different age groups. Am J Physiol - Endocrinol Metab 277: . doi: https://doi.org/10.1152/ajpendo.1999.277.3. e489

48. 48. Bredella MA, Ghomi RH, Thomas BJ, et al (2010) Comparison of DXA and CT in the assessment of body composition in premenopausal women with obesity and anorexia nervosa. Obesity 18:2227-2233 . doi: https://doi.org/10.1038/oby.2010.5

49. 49. Messina C, Bandirali M, Sconfienza LM, et al (2015) Prevalence and type of errors in dual-energy x-ray absorptiometry. Eur Radiol 25:1504-1511 . doi: https://doi.org/10.1007/ s00330-014-3509-y

50. 50. Sjostrom L, Kvist H, Cederblad A, Tylen U (1986) Determination of total adipose tissue and body fat in women by computed tomography, 40K, and tritium. Am J Physiol - Endocrinol Metab 250: . doi: https://doi.org/10.1152/ajpendo.1986.250.6.e736

51. 51. Sergi G, Trevisan C, Veronese N, et al (2016) Imaging of sarcopenia. Eur J Radiol 85:1519-1524 . doi: https://doi.org/10. 1016/j.ejrad.2016.04.009

52. 52. Albano D, Chianca V, Tormenta S, et al (2017) Old and new evidence concerning the crucial role of ultrasound in guiding intra-articular injections. Skeletal Radiol 46:963-964 . doi: https://doi.org/10.1007/s00256-017-2644-3

53. 53. Amini B, Boyle SP, Boutin RD, Lenchik L (2019) Approaches to assessment of muscle mass and myosteatosis on computed tomography: A systematic review. Journals Gerontol. - Ser. A Biol. Sci. Med. Sci. 74:1671-1678

54. 54. Boutin RD, Kaptuch JM, Bateni CP, et al (2016) Influence of IV contrast administration on ct measures of muscle and bone attenuation: Implications for sarcopenia and osteoporosis evaluation. Am J Roentgenol 207:1046-1054 . doi: https://doi.org/10. 2214/AJR.16.16387

55. 55. Derstine BA, Holcombe SA, Goulson RL, et al (2018) Quantifying Sarcopenia Reference Values Using Lumbar and Thoracic Muscle Areas in a Healthy Population. J Nutr Heal Aging 22:180-185 . doi: https://doi.org/10.1007/s12603-017-0983-3

56. 56. Derstine BA, Holcombe SA, Ross BE, et al (2018) Skeletal muscle cutoff values for sarcopenia diagnosis using T10 to L5 measurements in a healthy US population. Sci Rep 8:11369 . doi: https://doi.org/10.1038/s41598-018-29825-5

57. 57. Zannoni S, Albano D, Jannone ML, et al (2020) Correlation between muscle mass and quality around the hip and of psoas muscles at L3 level using unenhanced CT scans. Skeletal Radiol 49:1649-1655 . doi: https://doi.org/10.1007/s00256-020-03475-z

58. 58. Fischer MA, Pfirrmann CWA, Espinosa N, et al (2014) Dixonbased MRI for assessment of muscle-fat content in phantoms, healthy volunteers and patients with achillodynia: Comparison to visual assessment of calf muscle quality. Eur Radiol 24:13661375 . doi: https://doi.org/10.1007/s00330-014-3121-1

59. 59. Csapo R, Malis V, Sinha U, et al (2014) Age-associated differences in triceps surae muscle composition and strength - An MRI-based cross-sectional comparison of contractile, adipose and connective tissue. BMC Musculoskelet Disord 15:209 . doi: https://doi.org/10.1186/1471-2474-15-209

60. 60. Schlaeger S, Weidlich D, Klupp E, et al (2020) Water T 2 Mapping in Fatty Infiltrated Thigh Muscles of Patients With Neuromuscular Diseases Using a $\mathrm{T}_{2}$-Prepared 3D Turbo Spin Echo With SPAIR. J Magn Reson Imaging 51:1727-1736 . doi: https://doi.org/10.1002/jmri.27032

61. 61. Azzabou N, Hogrel JY, Carlier PG (2015) NMR based biomarkers to study age-related changes in the human quadriceps. Exp Gerontol 70:54-60 . doi: https://doi.org/10.1016/j.exger. 2015.06.015

62. 62. Albano D, Chianca V, Cuocolo R, et al (2018) T2-mapping of the sacroiliac joints at 1.5 Tesla: a feasibility and reproducibility study. Skeletal Radiol 47:1691-1696. doi: https://doi.org/ 10.1007/s00256-018-2951-3

63. Melville DM, Mohler J, Fain M, et al (2016) Multi-parametric MR imaging of quadriceps musculature in the setting of clinical frailty syndrome. doi: https://doi.org/10.1007/ s00256-015-2313-3

64. 64. Faghihi R, Zeinali-Rafsanjani B, Mosleh-Shirazi MA, et al (2017) Magnetic Resonance Spectroscopy and its Clinical Applications: A Review. J. Med. Imaging Radiat. Sci. 48:233-253

65. 65. Forbes SC, Lott DJ, Finkel RS, et al (2012) MRI/MRS evaluation of a female carrier of Duchenne muscular dystrophy. Neuromuscul Disord 22:S111 . doi: https://doi.org/10.1016/j.nmd. 2012.05.013

66. 66. Codari M, Zanardo M, Sabato ME, et al (2020) MRI-Derived Biomarkers Related to Sarcopenia: A Systematic Review. J Magn Reson Imaging 51:1117-1127 . doi: https://doi.org/10.1002/jmri. 26931

67. 67. Giraudo C, Cavaliere A, Lupi A, et al (2020) Established paths and new avenues: a review of the main radiological techniques for investigating sarcopenia. Quant Imaging Med Surg 10:1602-1613 . doi: https://doi.org/10.21037/qims.2019.12.15

68. 68. Guerini H, Omoumi P, Guichoux F, et al (2015) Fat Suppression with Dixon Techniques in Musculoskeletal Magnetic Resonance Imaging: A Pictorial Review. Semin. Musculoskelet. Radiol. 19:335-347

69. 69. Eggers H, Börnert P (2014) Chemical shift encoding-based water-fat separation methods. J Magn Reson Imaging 40:251268 . doi: https://doi.org/10.1002/jmri.24568

70. 70. Triplett WT, Baligand C, Forbes SC, et al (2014) Chemical shift-based MRI to measure fat fractions in dystrophic skeletal muscle. Magn Reson Med 72:8-19 . doi: https://doi.org/10.1002/ mrm. 24917

71. 71. Karampinos DC, Baum T, Nardo L, et al (2012) Characterization of the regional distribution of skeletal muscle adipose tissue in type 2 diabetes using chemical shift-based water/fat separation. J Magn Reson Imaging 35:899-907 . doi: https://doi.org/ 10.1002/jmri.23512

72. 72. Chianca V, Albano D, Messina C, et al (2017) Diffusion tensor imaging in the musculoskeletal and peripheral nerve systems: from experimental to clinical applications. Eur Radiol Exp 1:12 . doi: https://doi.org/10.1186/s41747-017-0018-1

73. 73. Barp A, Carraro E, Albamonte E, et al (2020) Muscle MRI in two SMA patients on nusinersen treatment: A two years followup. J Neurol Sci 417:117067 . doi: https://doi.org/10.1016/j.jns. 2020.117067

74. 74. Vetrano IG, Sconfienza LM, Albano D, et al (2019) Recurrence of carpal tunnel syndrome in isolated non-syndromic macrodactyly: DTI examination of a giant median nerve. 
Skeletal Radiol 48:989-993 . doi: https://doi.org/10.1007/ s00256-018-3098-y

75. 75. Ponrartana S, Ramos-Platt L, Wren TA (2015) Effectiveness of diffusion tensor imaging in assessing disease severity in Duchenne muscular dystrophy: preliminary study. Pediatr Radiol 45: . doi: https://doi.org/10.1007/s00247-014-3187-6

76. 76. Sconfienza LM, Albano D, Allen G, et al (2018) Clinical indications for musculoskeletal ultrasound updated in 2017 by European Society of Musculoskeletal Radiology (ESSR) consensus. Eur Radiol 28(12):5338-5351. doi: https://doi.org/10.1007/ s00330-018-5474-3

77. 77. Pillen S, van Alfen N (2011) Skeletal muscle ultrasound. Neurol. Res. 33:1016-1024

78. 78. Abe T, Fujita E, Thiebaud RS, et al (2016) UltrasoundDerived Forearm Muscle Thickness Is a Powerful Predictor for Estimating DXA-Derived Appendicular Lean Mass in Japanese Older Adults. Ultrasound Med Biol 42:2341-2344 . doi: https:// doi.org/10.1016/j.ultrasmedbio.2016.05.008

79. 79. Thomaes T, Thomis M, Onkelinx S, et al (2012) Reliability and validity of the ultrasound technique to measure the rectus femoris muscle diameter in older CAD-patients. BMC Med Imaging 12:7 . doi: https://doi.org/10.1186/1471-2342-12-7

80. 80. Sanada K, Kearns CF, Midorikawa T, Abe T (2006) Prediction and validation of total and regional skeletal muscle mass by ultrasound in Japanese adults. Eur J Appl Physiol 96:24-31 . doi: https://doi.org/10.1007/s00421-005-0061-0

81. 81. Nijholt W, Scafoglieri A, Jager-Wittenaar H, et al (2017) The reliability and validity of ultrasound to quantify muscles in older adults: a systematic review. J. Cachexia. Sarcopenia Muscle 8:702-712

82. 82. English C, Fisher L, Thoirs K (2012) Reliability of real-time ultrasound for measuring skeletal muscle size in human limbs in vivo: A systematic review. Clin. Rehabil. 26:934-944

83. 83. Guerri S, Mercatelli D, Gómez MPA, et al (2018) Quantitative imaging techniques for the assessment of osteoporosis and sarcopenia. Quant. Imaging Med. Surg. 8:60-85

84. 84. Perkisas S, Baudry S, Bauer J, et al (2018) Application of ultrasound for muscle assessment in sarcopenia: towards standardized measurements. Eur Geriatr Med 9:739-757 . doi: https:// doi.org/10.1007/s41999-018-0104-9

85. 85. Kawakami Y, Abe T, Fukunaga T (1993) Muscle-fiber pennation angles are greater in hypertrophied than in normal muscles. J Appl Physiol 74:2740-2744 . doi: https://doi.org/10.1152/jappl. 1993.74.6.2740

86. 86. Ikezoe T, Mori N, Nakamura M, Ichihashi N (2011) Agerelated muscle atrophy in the lower extremities and daily physical activity in elderly women. Arch Gerontol Geriatr 53: . doi: https://doi.org/10.1016/j.archger.2010.08.003

87. 87. Ticinesi A, Narici M V., Lauretani F, et al (2018) Assessing sarcopenia with vastus lateralis muscle ultrasound: an operative protocol. Aging Clin Exp Res 30:1437-1443 . doi: https://doi. org/10.1007/s40520-018-0958-1

88. 88. Randhawa A, Wakeling JM (2013) Associations between muscle structure and contractile performance in seniors. Clin Biomech 28:705-711 . doi: https://doi.org/10.1016/j.clinb iomech.2013.04.010

89. 89. Aagaard P, Andersen JL, Dyhre-Poulsen P, et al (2001) A mechanism for increased contractile strength of human pennate muscle in response to strength training: Changes in muscle architecture. J Physiol 534:613-623 . doi: https://doi.org/10.1111/j. 1469-7793.2001.t01-1-00613.x

90. 90. Alfuraih AM, Tan AL, O'Connor P, et al (2019) The effect of ageing on shear wave elastography muscle stiffness in adults. Aging Clin Exp Res 31:1755-1763 . doi: https://doi.org/10.1007/ s40520-019-01139-0

91. 91. Mitchell WK, Phillips BE, Williams JP, et al (2013) Development of a new sonovue ${ }^{\mathrm{TM}}$ contrast-enhanced ultrasound approach reveals temporal and age-related features of muscle microvascular responses to feeding. Physiol Rep 1: . doi: https://doi.org/10. 1002/phy2.119

92. Sconfienza LM (2019) Sarcopenia: ultrasound today, smartphones tomorrow? Eur. Radiol. 29

93. 93. Panch T, Szolovits P, Atun R (2018) Artificial intelligence, machine learning and health systems. J Glob Health 8: . doi: https://doi.org/10.7189/jogh.08.020303

94. 94. Gitto S, Cuocolo R, Albano D, et al (2020) MRI radiomicsbased machine-learning classification of bone chondrosarcoma. Eur J Radiol 128:109043 . doi: https://doi.org/10.1016/j.ejrad. 2020.109043

95. 95. Erickson BJ, Korfiatis P, Akkus Z, Kline TL (2017) Machine learning for medical imaging. Radiographics 37:505-515 . doi: https://doi.org/10.1148/rg.2017160130

96. 96. Chianca V, Cuocolo R, Gitto S, et al (2021) Radiomic Machine Learning Classifiers in Spine Bone Tumors: A MultiSoftware, Multi-Scanner Study. Eur J Radiol 137:109586 . doi: https://doi.org/10.1016/j.ejrad.2021.109586

97. 97. Polan DF, Brady SL, Kaufman RA (2016) Tissue segmentation of computed tomography images using a Random Forest algorithm: A feasibility study. Phys Med Biol 61:6553-6569 . doi: https://doi.org/10.1088/0031-9155/61/17/6553

98. 98. Dong X, Dan X, Yawen A, et al (2020) Identifying sarcopenia in advanced non-small cell lung cancer patients using skeletal muscle $<\mathrm{scp}>\mathrm{CT}</ \mathrm{scp}>$ radiomics and machine learning. Thorac Cancer 11:2650-2659 . doi: https://doi.org/10.1111/ 1759-7714.13598

99. 99. Lenchik L, Barnard R, Boutin RD, et al (2021) Automated muscle measurement on chest CT predicts all-cause mortality in older adults from the National Lung Screening Trial. Journals Gerontol - Ser A Biol Sci Med Sci 76:277-285 . doi: https://doi. org/10.1093/gerona/glaa141

100. 100. Barnard R, Tan J, Roller B, et al (2019) Machine Learning for Automatic Paraspinous Muscle Area and Attenuation Measures on Low-Dose Chest CT Scans. Acad Radiol 26:1686-1694 . doi: https://doi.org/10.1016/j.acra.2019.06.017

101. 101. Kim YJ (2021) Machine learning models for sarcopenia identification based on radiomic features of muscles in computed tomography. Int J Environ Res Public Health 18:8710 . doi: https://doi.org/10.3390/ijerph18168710

Publisher's Note Springer Nature remains neutral with regard to jurisdictional claims in published maps and institutional affiliations. 